\title{
EDITORIAL
}

\section{Música e infancia}

En 2014 los investigadores Daniela Banderas Grandela, Juan Carlos Poveda Viera y el autor de estas líneas llegamos al convencimiento de que era necesario comenzar a estudiar de una manera más sistemática el tema de la música y la infancia en el contexto chileno desde una perspectiva musicológica. Así, en el IX Congreso Chileno de Musicología, realizado en julio de 2017, se presentó una mesa titulada "Música, educación e infancia" donde Daniela, Juan Carlos y la socióloga Loreto de la Fuente Labbé presentaron sus avances de investigación en este campo. Y en el presente número (230) de Revista Musical Chilena se concreta finalmente un primer aporte colectivo en este aspecto, con un conjunto de trabajos que, desde diferentes ángulos y abarcando diferentes objetos específicos de estudio, abordan este tema. Agradecemos así a los autores mencionados y también a Francisca Meza Bernstein y Tania Ibáñez Gericke por su participación en este esfuerzo. Esperamos que sea solo un primer paso para la profundización de líneas de estudio y para comenzar a dialogar con colegas de otros países latinoamericanos en torno a este tema.

Junto con este conjunto de estudios se presenta un texto muy oportuno escrito por Yavet Boyadjiev que aporta nuevos antecedentes acerca del violinista y compositor afrocubano José White Laffite (1836-1918), de quien en este año 2018 se cumple el primer centenario de su fallecimiento. En este texto se presenta información muy interesante acerca de su gira por Estados Unidos entre 1875 y 1876 , y las proyecciones posibles que esto tuvo en la siguiente etapa de su carrera en Latinoamérica.

Agradecemos además a Daniela Fugellie Videla por su trabajo de edición de los documentos acerca del Festival Pedro Humberto Allende realizado en septiembre de 2017, así como a sus autores, Juan Allende-Blin (recientemente galardonado con el Premio Nacional de Artes Musicales 2018) y Luis Merino Montero.

Asimismo gracias a Vladimir Barraza Jeraldo y Álvaro Gallegos Marino por sus aportes a la sección de crónica, a quienes han colaborado en la redacción de reseñas (Marco Antonio de la Ossa, Nicolás Masquiarán Díaz, Joaquín Molina, Marianne Rippes y Pablo Rojas Sahurie), resúmenes de tesis (Pablo Catrileo, Jorge Canales, Javier Paredes y Osiel Vega Durán) y en la sección de In memoriam (Lina Barrientos Pacheco, Julio Garrido Letelier, Álvaro Menanteau Aravena, Miguel Vera Cifras y Carlos Zamora Pérez).

Cristián Guerra Rojas

Director

Revista Musical Chilena cguerrar@uchile.cl 